\title{
Wine fingerprinting using a bio-geochemical approach
}

José Ramiro Fernandes ${ }^{1,2}$, Leonor Pereira ${ }^{3}$, Pedro Jorge ${ }^{4}$, Luis Moreira ${ }^{2,3}$, Helena Gonçalves ${ }^{2,3}$, Luis Coelho ${ }^{1}$, Daniel Alexandre ${ }^{1,2}$, José Eiras-Dias ${ }^{4}$, João Brazão ${ }^{4}$, Pedro Clímaco ${ }^{4}$, Margarida Baleiras-Couto ${ }^{4}$, Sofia Catarino ${ }^{5}$, António Graça ${ }^{6}$, and Paula Martins-Lopes ${ }^{2,3}$

\author{
${ }^{1}$ INESC TEC, Rua do Campo Alegre n. 687, 4169-007 Porto, Portugal \\ ${ }^{2}$ University of Trás-os-Montes and Alto Douro, Apartado 1013, 5000-911 Vila Real, Portugal \\ ${ }^{3}$ Center of Agricultural Genomics and Biotechnology (CGBA), University of Trás-os-Montes, and Alto Douro, Apartado \\ 1013, 5000-911 Vila Real, Portugal \\ ${ }^{4}$ INIAV Dois Portos Quinta d'Almoínha, 2565-191 Dois Portos, Portugal \\ ${ }^{5}$ LEAF - Instituto Superior de Agronomia, Universidade de Lisboa, Tapada da Ajuda, 1349-017 Lisboa, Portugal \\ ${ }^{6}$ Sogrape Vinhos S.A., 4430-809 Avintes, Portugal
}

\begin{abstract}
The wine sector is a billion euro business and therefore subjected to multiple attempts of fraudulent practices. This requires the development of rapid and reliable methods to detect such situations. Several methodologies have been developed based on the chemical profiles of the wines, but they are limited due to the environmental conditions that cannot be controlled. The use of DNA-based detection systems are an emergent research field that have been extended to a wide variety of food products and are still the most reliable methods for varietal identification. However these methods are not suitable for geographical determination. Soil related fingerprints have a primary role considering that there is a relationship between the elemental composition of wine and the composition of the provenance soil. WineBioCode is a project aiming to define the best strategy for wine authenticity based on a multidisciplinary approach. Two DNA-based strategies have been developed based on Real-time PCR and a label free optical biosensor platform. Both platforms enabled successful identification of specific DNA-targets when applied to Vitis vinifera L., and can be applied throughout the grape-wine chain. The methods are complementary and can be used in different situations, according to the requirements. The geographical evaluation has been assessed by the strontium ${ }^{87} \mathrm{Sr} /{ }^{86} \mathrm{Sr}$ isotope ratio determination involving soil evaluation in the vineyards followed by its assay in the wine samples. The results are being integrated in order to establish the best procedure to be undertaken for wine fingerprinting, including varietal composition and geographical origin, therefore fulfilling the requirements of the geographical denominations in wine certification.
\end{abstract}

\section{Introduction}

The authenticity of food products is a major problem worldwide. The European Union (EU) has protected its major food products through defined regulations, such as Regulation 510/2006 [1], intending to increase consumers trust and to protect producers.

Although several traceability systems have been regulated and implemented throughout the food chain, they are mainly based on a digital control ensured by a code placed on the products' label to guarantee quality and to prevent outbreaks related to food adulterations. However, the detection of food adulterations are still a challenging analytical concern in many food matrices. In wine, the same variety is subjected to different growing and production conditions, which will affect the respective fingerprinting [2]. Therefore, there is a need to develop the best methodologies suitable to unequivocally identify the wine.

Food fingerprinting can be differentiated at different levels, e.g., botanical, geographical origin or adulteration. WineBioCode is interested in targeting the first two, once these are directly related to the Denomination of Origin (DO) designations and maybe used to define regulatory measures for wine certification purposes (Fig. 1).

A recent review in the field [3] refers that some of the mostly wide applied methods for botanical and geographical origin in wine are spectroscopic and/or spectrometric, such as, HS-SPME; UPLC; FT-ICR-MS; H NMR; UVvis; NIR; MIR; HPLC; GCMS, among others. All these are high-throughput approaches requiring the use of more or less complex statistical analyses [3] and most of the times an intense data collection from the defined region considering several production years and varieties, in order to develop a reliable database.

Nonetheless, there are some difficulties to distinguish varietal composition of wines using only spectroscopic and/or spectrometric approaches [2]. Nowadays, DNAbased techniques are being applied for food authenticity purposes [4]. One of the major reasons of its wide application is that it allows a correct varietal fingerprinting throughout the entire wine-chain, being independent of the growing and production conditions. The main constrain 


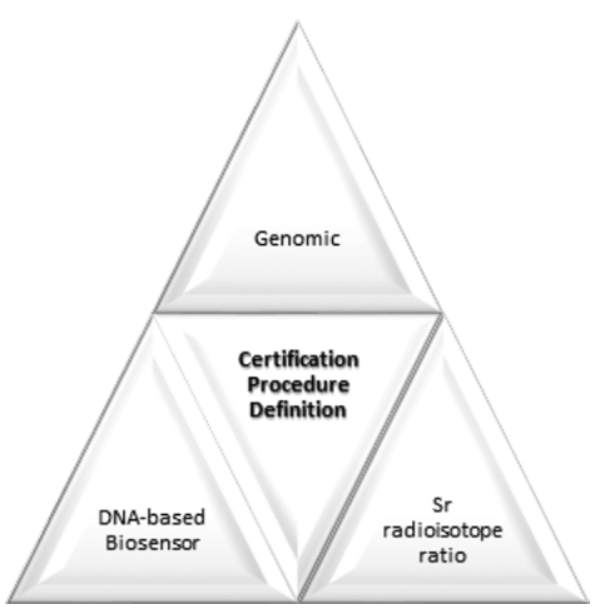

Figure 1. Strategies adopted within WineBioCode to define the best procedure for certification purposes.

linked to their wide application in wines is associated to the quality and quantity of DNA extracted from the wine samples, given the fact that DNA can be highly degraded during the winemaking process (decanting and filtration), stabilization (clarification and racking) and aging [5]. Several DNA extraction protocols have been developed through the years [5-7]. The protocol developed by Pereira et al. [7] has demonstrated to be able to extract DNA from small volume wine samples, $10 \mathrm{~mL}$, and free of enzymatic inhibitors, therefore suitable for PCR-based technologies. As previously mentioned DNA extracted from wine samples are highly degraded, and therefore this needs to be taken into account when choosing the molecular markers for varietal identification. The recommended amplicon size is around 100-120 bp [4]. The molecular markers of choice are Single Nucleotide Polymorphism (SNP) based markers, once they are highly abundant within the genomes. Several methodologies have been developed to detect SNP markers, SSCP, Sequencing, Arrays, among others, however, the High Resolution Melting has been recently widely explored with good results [8].

The use of biosensors in the food industry is increasing and are now mainly focused on food packaging for quality control, mostly linked to food borne detection [9]. The use of DNA-based biosensors is an emerging field in the area of food authenticity, presenting several advantages in relation to PCR-based technologies, such as, lower cost, faster detection, portability, and can be operated by untrained technicians. Several technologies can be used for this purpose but the optical biosensors have the advantage of speed and reproducibility. Among them, the optical fiber based biosensors are of special interest because they can use the optoelectronic components developed for the telecommunications industry with great advantages in terms of cost and can be easily integrated with computer systems that can perform intensive data analysis of the measured data in real time.

Although the varietal identification may be achieved using molecular markers within a wine, the grape origin cannot be detected by these means. Regarding geographical origin, soil related fingerprints have a primary role considering that there is a relationship between the chemical composition of wine and the composition of the provenance soil, in particular the ${ }^{87} \mathrm{Sr} /{ }^{86} \mathrm{Sr}$ ratio, being a very interesting approach for the definition of the different Denominations of Origin [10].

The aim of this paper is to present some preliminary results within the WineBioCode frame, targeting the definition of certification procedures suitable for wine authenticity purposes.

\section{Material and methods}

\subsection{Plant material, soil and wine sampling}

Grapevine varieties were selected in relation to their relevance for Douro Wine Appellation. A total of 22 varieties were used, 7 white and 15 red grapevine varieties. The vineyards were located in the Douro Wine Region, belonging to three enterprises (Sogrape Vinhos S.A. and Real Companhia Velha).

Soil sampling took place between February and June 2013 in the following estates: Seixo, Cavernelho, Boavista, Cidrô and Casal da Granja. In each vineyard, and for each grape variety, soil samples were collected with a probe, from 2 sampling sites, considering two depth layers $(20-50,50-80 \mathrm{~cm})$, and sealed in plastic bags. Soil samples were dried, ground and then forced to pass through a $50 \mu \mathrm{m}$ sieve.

The leaf samples were collected to serve as references throughout the project and grapes were harvested in two consecutive years 2012/13 and 2013/14. The grapes were fermented in controlled conditions and wines were stored in individual bottles that were used throughout the project.

Leaf samples were collected from clonal field collections, in order to confirm the molecular markers obtained for each variety under study.

\subsection{DNA extraction}

DNA extraction from leaf samples was conducted using the CTAB method [11] with minor modifications. The wine samples were extracted according to Pereira et al. [7]. DNA concentration was determined using NanoDrop ${ }^{\circledR}$ ND-1000 spectrophotometer (Nanodrop Technologies, Wilmington, DE, USA).

\subsection{Sequencing and SNP discovery}

In silico analysis of UFGT gene sequence (coding for UDP glucose-flavonoid 3-O-glucosyl-transferase) was performed and primer pairs were designed using Prime 3 software. The sequences were obtained for the whole set of grapevine varieties and SNPs were annotated. These sequences were further used in the development of HRM assay.

\subsection{DNA based detection methods for varietal identification}

\subsubsection{PCR based methods}

PCR was performed in a total volume of $20 \mu \mathrm{L}$ using MeltDoctor ${ }^{\mathrm{TM}}$ HRM Master Mix containing SYTO ${ }^{\circledR} 9$ dye (Applied Biosystems). In addition, each reaction contained $5 \mu \mathrm{M}$ of each forward and reverse primer and $5 \mathrm{ng}$ of gDNA. The PCR amplification was conducted in a StepOne ${ }^{\mathrm{TM}}$ 
Real-Time PCR System (Applied Biosystems) as follows: initial denaturation of $10 \mathrm{~min}$ at $95^{\circ} \mathrm{C}$, followed by 40 cycles of $15 \mathrm{~s}$ at $95^{\circ} \mathrm{C}, 1 \mathrm{~min}$ at the optimal annealing $59^{\circ} \mathrm{C}$. Fluorescence was collected from 59 to $95^{\circ} \mathrm{C}$. The Melting curve analysis was carried out with High Resolution Melt Software v2.0 (Applied Biosystem).

\subsubsection{Biosensor}

The platform consisted on the functionalization of an optical fiber long-period grating (LPG) with single strand-DNA (specific to Vitis vinifera $\mathrm{L}$.). The LPG was made using an electric arc to produce fiber defects spaced of $398 \mu \mathrm{m}$. This produced an optical resonance in the transmitting spectra center at $1550 \mathrm{~nm}$ that was monitored with an optical sensor interrogator (HBM Fibersensig ${ }^{\text {TM }}$ FS2200SA) in the spectral range between 1500 and $1600 \mathrm{~nm}$. A spectra was acquired every two seconds and processed using a computer algorithm to determine the resonance spectral position. All assays were performed at constant temperature of $37^{\circ} \mathrm{C}$. The sensing system was put into contact with complementary sequence, partial-complementary and noncomplementary DNA in order to assure the occurrence of specific-hybridization. The hybridization was only assured in the presence of a complementary sequence.

\section{5. ${ }^{87} \mathrm{Sr} /{ }^{86} \mathrm{Sr}$ ratio analytical determination}

Wine samples were mineralized by adaptation of the HPMW procedure previously described [12]. Due to the isobaric overlap of ${ }^{87} \mathrm{Sr}$ and ${ }^{87} \mathrm{Rb}$, an effective $\mathrm{Rb} / \mathrm{Sr}$ separation is a pre-requisite for the accurate determination of Sr isotope ratios by Q-ICP-MS. In order to perform this separation, ion-exchange chromatography was carried out using EDTA as eluent [6].

Analytical measurements were carried out with a Perkin-Elmer SCIEX Elan 9000 ICP-MS. The contents of $\mathrm{Rb}$ and $\mathrm{Sr}$ in $\mathrm{Sr}$ chromatographic fractions were determined, using an ICP-MS semi-quantitative approach [13], before isotopic measurements. With the purpose of determining ${ }^{87} \mathrm{Sr} /{ }^{86} \mathrm{Sr}$ accurately, the SRM $987\left(\mathrm{SrCO}_{3}\right)$ from the NIST was used as isotopic standard for the instrumental mass bias correction [10]. Under optimized conditions samples were treated (HPMW digestion followed by chromatographic separation) and analysed in duplicate.

\section{Results and discussion}

The search for discriminative SNP markers was pursued within the genes involved in the flavonoid pathway, once this pathway is linked to the polyphenol compounds synthesis and these are highly variable among grapevine varieties [14]. The UFGT gene presented several SNPs at different positions within the varieties studied. These allowed to develop an HRM assay.

\subsection{HRM}

The High Resolution Melting assay demonstrated to be efficient in distinguishing between homozygous genotypes, Touriga Nacional (GG) and Tinto Cão (CC), and heterozygous genotypes, Touriga Franca (GC), for a given

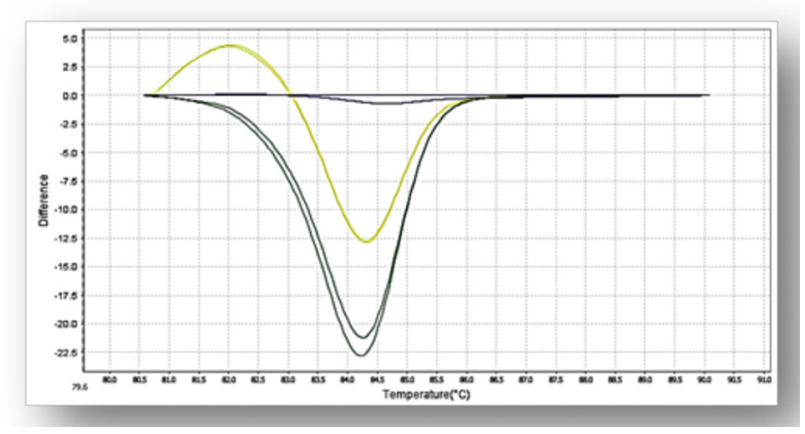

Figure 2. Derivate melting curves of the UFGT loci in three grapevine varieties: Touriga Nacional (GG, blue), Tinto Cão (CC, green) and Touriga Franca (GC, yellow).

region of the sequence (Fig. 2). Sanger sequencing of the amplicon in both directions confirmed the results obtained by HRM demonstrating the robustness of the assay.

A rapid and consistent genotyping is an important requirement for grapevine varietal identification. SNP are considered to be highly reproducible among labs and within different detection techniques. Nowadays, SNP detection methods are highly automated and are relatively inexpensive, making them one of the most widely used markers in plant wide applications. HRM assays detect these small sequence difference within a given amplicon [15], these small sequences are favourable when applying to processed food products, and particularly to wine [4].

\subsection{Biosensor}

The results obtained for this sensor are quite interesting, since they demonstrate that hybridization only occurs with total complementary DNA (Fig. 3).

The biosensor shows a high specificity as it is able to discriminate a complementary sequence from non-complementary sequence even when the non-complementary sequence presents a single nucleotide polymorphism

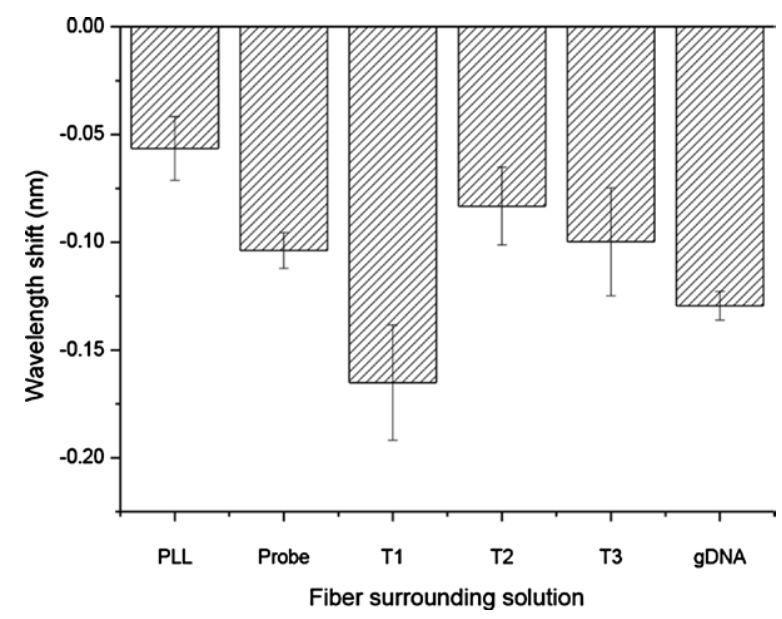

Figure 3. Wavelength shift average in relation to water wavelength. PLL - Poli-L-Lysine; Probe - ssDNA probe; T1 complementary sequence; T2 - non-complementary sequence; T3 - one mismatch complementary sequence; gDNA - genomic DNA of Vitis vinifera $L$. 
(SNP). The system was able to detect the complementary sequence present in a genomic DNA sample extracted from Vitis vinifera $L$.

The application of a DNA-based biosensor platform can overcome one of the biggest limitation of PCR based methods, which is the need to have a specialized handler. More even, the use of small DNA sequences as probes overcomes one of the most limiting constrains in wine authenticity, linked to the high DNA degradation found in the wine.

\section{3. ${ }^{87} \mathrm{Sr} /{ }^{86} \mathrm{Sr}$ ratio in wines}

Regarding the ${ }^{87} \mathrm{Sr} /{ }^{86} \mathrm{Sr}$ ratio, significant differences were found between wines. The lowest value $(0.7130)$ was observed in the following wines: Malvasia Fina (Quinta do Cavernelho), Pinot Noir (Quinta do Cidrô), Aragonez, Rufete, Touriga Franca, Touriga Nacional and Trincadeira (Quinta do Seixo). The wine Fernão Pires (Quinta do Casal da Granja) displayed the highest value (0.7175). It should be noted that the range of ${ }^{87} \mathrm{Sr} /{ }^{86} \mathrm{Sr}$ values $(0.7130-0.7175)$ is very narrow, reflecting the geographical proximity of the wines. These values are also in accordance with the scarce data available on wines from the Douro DO [16], a mainly schistous region.

\section{Conclusion}

The search for reliable certification methods in food products is a major concern in the European Union. The wine sector can be considered as a sensible target to fraudulent practise mainly in highly quoted wines, therefore there is an urgent need to develop reliable certification procedures for the chain.

The integrated approach used within WineBioCode is foreseeing that DNA based methods may be widely used in wine varietal composition, once the fingerprinting is not altered throughout the production chain, guarantying both reliability and feasibility. The two complementary methodologies developed are targeting different environmental testing. The HRM based methodology will target a fine testing aiming to screen for a wider gamma of varieties in one particular assay with specialized technician; whereas the biosensor will target a broader usage targeting defined varieties. This last system is cheaper and simpler than the currently available methods for DNA detection and therefore it can be seen as a competitive technology in the field.
When considering a Denomination of Origin it is imperative that a geographical certification is considered. The use of a geological fingerprinting is one of the most promising methodologies. Even though our preliminary results present some evidences, there is a need for a systematic geological characterization of the regions so it may be widely applied throughout the different regions worldwide.

\section{References}

[1] Council Regulation (EC) No 510/2006, Off. ]. Eur. Union, L93, 12 (2006)

[2] F. Fang, J.M. Li, P. Zhang, K Tang, W. Wang, Q.H. Pan, W.D. Huang, Food Res. Int., 41, 53-60 (2008)

[3] S. Esslinger, J. Riedl, C. Fauhl-Hassek C. Food Res. Int., 60, 189-204 (2014)

[4] P. Martins-Lopes, S. Gomes, L. Pereira, H. GuedesPinto, Food Technol. Biotech., 51, 198-207 (2013)

[5] E. Garcia-Beneytez, M.V. Moreno-Arribas, J. Borrego, M.C. Polo, J. Ibanez, J. Agric. Food Chem., 50, 6090-6096 (2002)

[6] M.D. Baleiras-Couto, J.E. Eiras-Dias, Anal. Chim. Acta, 563, 283-291 (2006)

[7] L. Pereira, H. Guedes-Pinto, P. Martins-Lopes. Amer. J. Enol. Vitic., 62, 547-552 (2011)

[8] A. Pietzka, A. Indra, A. Stoger, J.Zeinzinger, M. Konrad, P. Hasenberger, F. Allerberger, W. Ruppitsch, J. Antimic. Chem., 63, 1121-1127 (2009)

[9] C. Lopes, J.R. Fernandes, P. Martins-Lopes, Food Technol. Biotech., 51, 183-197 (2013)

[10] P. Martins, M. Madeira, F. Monteiro, R. Bruno de Sousa, A.S. Curvelo-Garcia, S. Catarino, J. Inter. Sci. Vigne Vin, 48, 21-29 (2014)

[11] J.J. Doyle, J.L. Doyle, Focus, 12, 13-15 (1987)

[12] S. Catarino, I.M. Trancoso, M. Madeira, F. Monteiro, R. Bruno de Sousa, A.S. Curvelo-Garcia Bulletin de l'OIV, 84 (965-967), 223-246 (2011)

[13] S. Catarino, A.S. Curvelo-Garcia, R. Bruno de Sousa, Talanta, 70, 1073-1080 (2006)

[14] G. Picariello, P. Ferranti, G. Garro, G. Manganiello, L. Chianese, R. Coppola, F. Addeo, Food Chem., 146, 15-22 (2014)

[15] M. Liew, R. Pryor, R. Palais, C. Meadows, M. Erali, E. Lyon, C. Wittwer, Clin Chem., 50, 1156-1164 (2004)

[16] C.M. Almeida, M.T.S.D. Vasconcelos, Food Chem., 85, 7-12 (2004) 